\title{
Healthcare Inaccessibilities Challenged Through Podcasts
}

\author{
Samantha Lee ${ }^{1}$ and Vilma Ortiz ${ }^{1}$ \\ ${ }^{1}$ University of California (UCLA), Los Angeles, CA, USA \\ DOI: https://doi.org/10.47611/jsr.v10i1.1136
}

\section{$\underline{\text { ABSTRACT }}$}

Podcasting has become a form of disseminating information as well as for advocating social change. This paper utilizes the popular mainstream form of artivism (podcasts) in order to underscore the disparities in the healthcare system that specifically affect the Latinx community. These social inequalities that provide a lack of access to care include language/cultural barriers, geographical accessibility, and the cost of health care. These various podcasts use personal anecdotes and statistics to highlight the gaps in our healthcare system and to encourage the listeners to advocate for change.

\section{Introduction}

Access to affordable and equitable healthcare in the United States has been a salient obstacle in society for countless minorities, in particular the Latinx community. The term Latinx is a gender-neutral term used to categorize people of Latin American descent. Salud America, a Latinx health podcast, challenges forms of oppression and social injustice in the United States by empowering underprivileged communities through the use of media outlets. Podcasts are becoming an exponentially growing media production platform that fosters advocates for the voiceless, uniting and empowering them to challenge the social disparities they face by providing information, inspiring solidarity and unifying communities. In the United States alone, $75 \%$ of Americans are familiar with podcasts, and this percentage is similar for other countries around the world (Edison Research). Podcasting is becoming a convenient way to disseminate information about a variety of topics, including invaluable healthcare advice, to hundreds of millions of listeners around the world. The Latinx community has felt the brunt of the inequalities of the healthcare system because of language barriers, accessibility, and cost that stands in their way of maintaining their health. Salud America is a powerful force that educates the audience about ways to approach these barriers to affordable and accessible healthcare, while also encouraging opposition to these disparities in order to promote social justice through change. Salud America appeals to two different audiences through its messages, those who need care and help in minimizing the barriers they face, and those who have the power to advocate for change in the healthcare system. Salud America's platform challenged several accessibility disparities in the healthcare system that prevent social equality: language and cultural barriers, geographic accessibility of the healthcare system, and the cost of healthcare.

\section{Language and Cultural Barriers}

The Latinx community has experienced many hardships, one being the language and cultural barrier of the healthcare system. Many podcasts, like Salud America, challenge these barriers by informing the audience about strong religious beliefs, culturally taboo subjects, like sexual health or mental illness, language barriers, and lack of culturally competent Latinx healthcare professionals (Machado 2014). Salud America produced an episode titled "Breaking Traditions," which framed its theme around how the healthcare system needs to be culturally aware in order to aid patients 
in the best manner possible. The guest speaker, Dr. Daniel Carlos Hughes, who is currently working on a holistic medical approach with a team at UT Health San Antonio MD Anderson Cancer Center, argued that "doctors must combine their medical and personal advice" to better help their patients' mind, body, and spirit (McCormack 2020). The Latinx community is known for being very culturally traditional and maintaining strong religious beliefs. Because of these strong religious and cultural ties, "72 percent of Hispanics never use prescription drugs" because many "Latinos - particularly those from indigenous backgrounds - have an established history of using natural medicine" (Machado 2014). This lack of cultural knowledge that the medical community has can cause discomfort and lack of trust in doctors that can further harm the patient by their refusal to return to the hospital for care. This conveys how salient the cultural barrier is in the healthcare system because if medical professionals do not understand a certain cultural background of patients, they will prescribe the wrong treatment, or the patient will just refuse to take the medicine, causing harm to the patient. Culturally competent doctors can improve the healthcare system if they are able to understand the Latinx culture and religious background in order to find a specialized and individualized treatment for each individual patient.

However, the lack of Latinx doctors is a barrier that is structurally rooted in the healthcare system. Only $5.8 \%$ of physicians and $2 \%$ of registered nurses identify as Hispanic (Conrad 2020). With this disparity in the number of healthcare professionals, the access to healthcare professionals that understand the Latinx community is limited, especially when many patients are not proficient in English. The number of healthcare professionals who are Hispanic and actually speak Spanish is even lower than the already low percentages stated above. This is one of the many inequalities the Latinx community faces within the healthcare system. In fact, "nearly 6 in 10 Hispanic adults have had a difficult time communicating with a health care provider because of a language or cultural barrier," and when they do, they often turn to outside sources for help (Swanson 2018). Not being able to aptly communicate with the medical staff about their reason for seeking care and their cultural preferences when it comes to treatment can lead to a feeling of fear and hesitancy in returning to the medical facility.

Salud America challenges this form of social and systematic injustice through educating the audience about changes in the medical schools that are emphasizing cultural awareness in future doctors. One of Dr. Hughes' colleagues, Dr. Labatora, who recently graduated from medical school, addressed this health inequity. Dr. Labatora conveyed how the social determinants of health were now being underscored in medical school in order to address each patient as an individual who has their own experiences and background. Dr. Labatora then thanked Salud America for spreading awareness of this inequality and bringing this conversation about healthcare injustice into the forefront of the audience's mind. The hosts concluded this episode by imploring the audience to advocate for their community by passing new legislation, seeking more information, and encouraging others to act.

This new media production advocates for and enlightens the Latinx community by providing valuable insight showcasing that they are not alone in this oppression, while also appealing to the doctors to better support their patients by understanding their background. Podcasts are both necessary and effective in informing both patients and doctors of this disparity, enabling better communication and closing this gap in the healthcare system. Salud America's episode about challenging traditions addressed an interesting point, in which Dr. Hughes doesn't believe that the healthcare system should be a 'one size fits all approach' because there are still underlying disparities that are present preventing it from providing equality (McCormack 2020). Dr. Hughes believes that a uniform style of care and uniform cost will not close the healthcare gap because some groups need more intervention than other groups to actually achieve equality in the healthcare system. He argued that doctors need more training on cultural awareness in order to aptly treat everyone individually because of different backgrounds and traditions. Podcasts that rally like-minded individuals to a cause empower the community to enact social justice, such as how Salud America unites the listeners into changing the structure of the healthcare system to close this language and cultural disparity. 


\section{Geographic Accessibility of the Healthcare System}

Another social structure that perpetuates the inequality of the healthcare system is the geographic inaccessibility of the system that is maintained through the lack of nearby hospitals and doctors in rural areas. Salud America produced an episode titled "Healthcare Access, or Lack Thereof," which documented the social and geographic barriers to accessible healthcare. Mateo Binagas, the guest speaker is a health advocate who brings awareness to and inspires change for healthcare injustice. He lives in San Antonio, Texas, and discusses how where one lives geographically can lead to inaccessible healthcare. Binagas was not aware of this grim reality for many since he lived in an urban city in Texas that has hospitals within miles of each other; however, when Binagas discovered this injustice of inaccessible access to care, he decided to become an expert researcher on advocating for social change.

The access of healthcare is not just inaccessible because of the shortage of minority doctors who do not have the cultural awareness and language skills to help the patients, it is also geographically inaccessible. Binagas detailed how many Latinos in border towns have to take off a day of work to travel to the nearest hospital for services, which could be hundreds of miles away. For many, taking off work to seek medical attention is not an option they can afford, so many do not seek treatment, or seek other alternatives for help. He also conveyed that doctors and other healthcare professionals are more likely to work in urban areas than in rural areas due to better salaries, which further exacerbates the lack of doctors in rural areas. In rural areas, farm workers are "exposed to pesticides in their work, and the children of these families also have a higher risk of exposure," which is compounded with the lack of healthcare access in rural areas (Adler 2006). This geographical discrepancy in the access to healthcare, prevalent in Salud America, allows the artivism to take hold and promote social justice when it comes to the inaccessibility of the healthcare system.

Although there are more doctors in urban areas as opposed to rural areas, major cities also have a shortage of healthcare professionals, which puts a strain on the already scarce resources in rural areas. The Covid-19 pandemic has put stress and strain on the medical system, causing hundreds of thousands to be hospitalized in the United States, and abroad. The lack of resources in the healthcare system (healthcare professionals, medicine, and other resources) is being felt across the United States, in cities and rural areas alike. The podcast episode " 24 Hours in a Brooklyn Hospital" by The New York Times illustrated how this pandemic strains the healthcare system as the doctor being interviewed in the episode amplified the need for "more nurses" and "more doctors" (Barbaro 2020). Doctors of all specialties are now working in the ICU to help give aid to the exponentially growing number of patients. This podcast episode was recorded in a Brooklyn hospital in a major city in New York. This is juxtaposed to the Salud America that showcased the lack of resources in rural areas. If major cities are lacking resources and staff amidst this pandemic and they already had more medical resources than the rural communities, the extremity of the stress placed on rural hospitals and clinics, coupled with their already scarce resources, showcases the healthcare disparity that the rural underserved communities face. With the shortage of doctors amidst this pandemic, many communities are also feeling the overwhelming trepidation of not being able to receive treatment if sick with the Coronavirus. This fear is exacerbated in rural areas where they face even more severe shortage of resources because of their geographic location. In addition, the Public Charge Rule under the Trump Administration threatens equal and accessible healthcare for all. The Public Charge Rule states that if an immigrant is using federal programs, such as food stamps and medical care, it can jeopardize their green card application and increase the likelihood of being denied (Futuro Media Group 2020). This has caused panic and trepidation among the immigrant communities because they don't want to chance forfeiting the possibility of a green card by receiving medical care if they contract the Coronavirus. However, the Public Charge Rule has clarified that it does not apply to COVID-19 related hospitalization services. Yet, this information is not well-known and podcasts are one method in disseminating this valuable and life-saving information. Large cities have better access to information and resources that can provide them with this important caveat. However, in isolated areas, like rural areas, information is not easily accessible, especially in border towns that speak multiple languages. This Public Charge Rule is just another example of a geographical barrier to accessible and equitable healthcare. 


\section{Cost of Healthcare}

Healthcare in the United States is very expensive, especially if one does not have health insurance. Salud America's episode titled "Healthcare Access, or Lack Thereof," also documented the economic barriers to accessible healthcare. The guest speaker Mateo Binagas, shared personal stories he has experienced in trying to close this gap. He helped an elderly woman in Texas, who had cancer and couldn't afford chemotherapy, so she declined treatment. Binagas also discovered that she was homeless and worked with her in finding a temporary home. This was the first instance that he realized how unjust the system was when this older woman who paid taxes her entire life and was now receiving social security checks, couldn't afford to receive health care. He continued to share how cancer doesn't discriminate, yet there is a disproportionate increase in Latinx mortality rate by cancer because they don't have the same access to the same resources. The doctor then elaborated on various resources that can help mitigate health care costs of cancer treatments through aid programs and nonprofit organizations. Bingas has continued to educate aspiring doctors and others interested in the medical field on the challenges of the healthcare system and how to best advise patients on treatments and resources available to help offset the cost. Salud America appeals to the audience in different ways to be effective in achieving their goal. This podcast episode concluded with encouraging listeners to reach out and contact their state representatives to enact change. This call to action was directed to those who have a privileged life and those who have power to help change the system. For the part of the audience that needs help in receiving care, they mentioned several resources they can seek out to get cost-aid help and non-profit organizations that provide free care. By appealing to different groups within the audience, the podcast is successful in promoting social justice and helping those who the healthcare system fails.

Healthcare is very expensive, but having health insurance reduces the out-of-pocket expenses of healthcare and has been shown to be the "single most important predictor of utilization" (Tienda 2006). Without health insurance coverage, many people find health care unaffordable and forgo receiving treatment even when they think they need it. Occupational health insurance is the primary way that individuals can have affordable healthcare. However, the "jobs available to recent and undocumented immigrants who lack proficiency in English are unlikely to provide health insurance as a benefit of employment" (Tienda 2006). Furthermore, under recent legislation, recent immigrants and noncitizens may receive fewer benefits than earlier immigrants and citizens from public health insurance programs; however, this varies depending on the state. For example, many Hispanics who live in states like Texas, Arizona, Florida and New Mexico, have more restrictive eligibility rules for Medicaid compared to states like New York and New Jersey who are less restrictive (Tienda 2006). The cost barrier to affordable healthcare is amplified in the following statistics: the probability of being uninsured among Hispanic Americans is $35 \%$ compared to $12.7 \%$ for whites (Tienda 2006). This disparity in insurance perpetuates this inequitable health care because many communities, like the Latinx community, is at a disadvantage of receiving affordable care because their jobs are less likely to provide health insurance. Therefore, since their jobs disproportionately do not provide health insurance, the Latinx community is more likely to not pay for healthcare insurance, which exponentially increases the cost of healthcare if they do need care. Salud America discussed this discrepancy because it leads to the Latinx community pushing off treatment because it is too expensive, which leads to additional healthcare problems later on. Salud America ended the episode by providing resources to receive cost aid so the community can receive care without draining the family financially.

The outrageous cost of healthcare has led to federally funded clinics that offer cost-free healthcare to help low-income communities. However, amidst this pandemic, the clinics are facing a lack of staffing and resources. Another informative podcast, Latino USA, produced an episode by showcasing how the struggle of the clinics is further exacerbated since the Senate didn't renew the federal funding plan for these clinics, which cut the clinics spending by $70 \%$ (Futuro Media Group 2020). This episode also referenced the same clinics that Salud America discussed in their episodes, underscoring the importance of these clinics to the Latinx community. The Latino USA episode concluded by encouraging the audience to donate to help these immigrant-prominent community clinics and to call representatives to renew the funding plan that supports equal and affordable access to healthcare. These clinics were the only method of receiving care for those who lacked affordable health insurance (McCormack 2020). This reoccurring 
problem of not being able to afford health insurance, and treatment, needed a solution. Under the Obama Administration, the Patient Protection and Affordable Care Act of 2010 was passed and allowed 20 million adults to gain health insurance coverage. Yet even as the number of uninsured has been significantly reduced, millions of Americans still lack coverage (Office of Disease Prevention and Health Promotion 2020). However, this act was a step in the right direction to close this healthcare gap and make healthcare more affordable. However, around $25 \%$ of Latinx adults in the U.S. are undocumented, making them unable to qualify for Medicaid or other government benefits. However, even with President Obama emphasizing that information provided when applying for Obamacare would not be transferred to immigration services, the " 5.5 million American-born children of undocumented parents may find their families avoiding Obamacare sign-ups out of fear of exposing their status" (Machado 2014). This preserves the unjust healthcare system and leaves millions of people vulnerable without the access to healthcare they can afford. Artivism through podcasts have promoted social change by disseminating information that could help close the cost gap of healthcare, while also advocating for legislative change to ensure that affordable healthcare is universal for all, despite race, legal status, and socioeconomic status. The podcast's method for achieving social justice differed among the audience. The patients and those in need of care were provided with information to available and cost-reduced resources, while doctors and other listeners who had the power to advocate change were encouraged to call for action by representatives through legislative change. Since the establishment of Salud America in 2007, the number of free medical clinics in the United States has increased from 1,007 clinics in 2007 to 1,400 clinics in 2021 (Darnell 2010 \& "National Association of Free and Charitable Clinics" 2021). Salud America has continued to host expert guest speakers and medical professionals in support of educating others on this topic by offering ways to get involved or become better educated on the subject at hand. This illustrates the power of knowledge and how social media and access to vital information can encourage those with the power to implement change to convert their goals into actions.

\section{Impact of Artivism}

The way society consumes media has changed; society is now more active on their phones and other hand-held devices, than reading newspapers and listening to the radio. This recent explosion of podcast listeners has led to podcasting as a mode of activism to enact social change in a society that is riddled with oppression and societal injustices. Podcasts, like Salud America, inspire many globally to challenge a plethora of disparities in health equality. Salud America addresses two distinct audiences that maximize the amount of social change that can be accomplished: individuals who need resources to minimize the disparities they face and those who have the power to change the system, such as doctors and other influential Latinx community members. Although Salud America's form of artivism persuasiveness is compelling, much government opposition is preventing change from being enacted in America to better the healthcare of residents. Salud America, and other podcasts, are advocates for the voiceless, uniting and empowering them to challenge the social disparities they face by providing information. Many minority communities, in particular the Latinx community that is the scope of this paper, is inspired to unite in solidarity, promote social change, and to combat the inequalities of the healthcare system. The valuable information presented in these podcasts are being made available to non-podcast listeners through the use of the internet by publishing the written transcript of the podcasts. These influential Latinx members are also quintessential examples of how vital information can be spread through communication with leading community members to ensure that the target audience of this information receives it. Salud America's mission is to serve the Latinx community via the dissemination of information, so their podcast episodes are free of charge and now readily accessible on the internet. Through the inspiration of new media production like podcasting, the language and culture barrier, geographical accessibility, and cost of the healthcare system can be challenged. Affordable and equal access to healthcare is a human right and by rallying communities around this cause, the institutionalized form of oppression can be eradicated. 


\section{Bibliography}

Adler, Nancy E. "Examining the Health Disparities Research Plan of the National Institutes of Health." Institute of Medicine (US) Committee on the Review and Assessment of the NIH's Strategic Research Plan and Budget to Reduce and Ultimately Eliminate Health Disparities, 2006. https://doi.org/10.17226/11602.

Barbaro, Michael. "24 Hours Inside a Brooklyn Hospital”. The Daily. New York Times, April 2020. https://www.nytimes.com/2020/04/15/podcasts/the-daily/coronavirus-brooklyn-hos pital.html

Conrad, Sarah S. "Diversity in Medicine: Facts and Figures 2019." Association of American Medical Colleges, AAMC, 2020, www.aamc.org/data-reports/workforce/interactive-data/figure-18-percentage-all-active-physicians-race/ethnicity-2018.

Darnell, Julie S. "Free Clinics in the United States: A Nationwide Survey." Health Care Reform, vol. 170, no. 11, 14 June 2010, pp. 946-953., doi:10.1001/archinternmed.2010.107.

Edison Research. “The Infinite Dial 2020.” Edison Research, Edison Research, 22 May 2020, www.edisonresearch.com/the-infinite-dial-2020/.

Futuro Media Group. "For Immigrant Communities, Coronavirus Is A Different Kind Of Threat". Latino USA. NPR, March 2020. https://www.npr.org/2020/03/24/821015833/for -immigrant- communities-coronavirus-is-a-different-kind-of-threat

Machado, Amanda. "Why Many Latinos Dread Going to the Doctor." The Atlantic. Atlantic Media Company, May 7, 2014. https://www.theatlantic.com/health/archive/2014/05/why -many-latinos-dread-going-to-the-doctor/361547/.

McCormack, Joshua. "Breaking Tradition". Salud Talks. Salud America, April 2020. https://podcasts.apple.com/us/podcast/healthcare-access-or-lack-thereof/id14773 $86373 ? \mathrm{i}=1000472284906$

McCormack, Joshua. "Healthcare Access, Or Lack Thereof". Salud Talks. Salud America, April 2020. https://podcasts.apple.com/us/podcast/healthcare-access-or-lack-thereof/id14773 $86373 ? \mathrm{i}=1000472284906$

"National Association of Free and Charitable Clinics." About Us $\mid$ National Association of Free and Charitable Clinics, National Association of Free and Charitable Clinics, 2021, www.nafcclinics.org/content/about-us.

Office of Disease Prevention and Health Promotion. "Access to Health Services." Healthy People 2020. U.S. Department of Health and Human Services. Accessed April 23, 2020. https://www.healthypeople.gov/2020/topics-objectives/topic/Access-to-Health-Services.

Swanson, Emily, and Russell Contreras. "Latinos, Hispanics Face Language Barriers In Health Care.” AARP Real Possibilities. American Association of Retired Persons, July 
27, 2018.https:/www.aarp.org/health/conditions-treatments/info-2018/ latinosHispanics-doctors-nursing-homes.html.

Tienda, Marta, and Faith Mitchell, eds. "Hispanics and the Future of America." Multiple Origins, Uncertain Destinies: Hispanics and the American Future, 2006. https://doi.org/10.17226/ 11539. 